\title{
Bond dissociation enthalpies calculated by the PM3 method confirm activity cliffs in radical scavenging of flavonoids
}

Dragan Amić • Bono Lučić • Goran Kovačević • Nenad Trinajstić

Published online: 27 November 2008

(C) Springer Science+Business Media B.V. 2008

\section{Erratum to: Mol Divers}

DOI 10.1007/s11030-008-9095-7

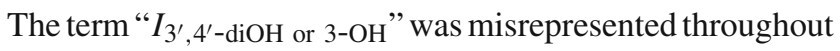
the original article. In addition to that error in Eq. 4, the minus sign was missing before the term " $0.251( \pm 0.241) \mathrm{BDE}_{\min }$ " in that equation. The correct equation is shown below.

$$
\begin{aligned}
& \mathrm{RSA}=85.27( \pm 71.66)+66.77( \pm 8.97) \\
& \quad I_{3^{\prime}, 4^{\prime}-\mathrm{diOH} \text { or } 3-\mathrm{OH}}-0.251( \pm 0.241) \mathrm{BDE}_{\min }
\end{aligned}
$$

The online version of the original article can be found under doi:10.1007/s11030-008-9095-7.

\section{Amić (凶)}

Faculty of Agriculture, The Josip Juraj Strossmayer University,

P.O. Box 719, 31107 Osijek, Croatia

e-mail:damic@pfos.hr

B. Lučić · G. Kovačević · N. Trinajstić

The Rugjer Bošković Institute, P.O. Box 180, 10002 Zagreb,

Croatia 